\title{
Our mission - reasons why we have chosen to launch a new international journal: HEART - VESSELS AND TRASNPLANTATION
}

Why to publish the new journal in English language on cardiovascular medicine in the international environment of abundance in specialized journals worldwide? It is reasonable to provide the rationale for this:

- There is a demand or need of young researchers and physicians in Central Asia and worldwide to read the latest advancements in medicine delivered without delays spent on translation and editing, and to share their research results and challenging case reports with international medical community, get the opinions of experts and also become the experts and reviewers of an international journal. We as a journal team, including editors (international team) and supporting services, have a goal and provide the truly international journal based on unbiased independent peer-review process to authors and readers and give them opportunity to get their research articles opinions of international experts, learn through reviewers reports and improve their articles to a level of high-quality research and present in an internationally accepted format and publish, in other cases of insufficient or lacking originality and quality have the thoughtful recommendations why the research articles are not accepted and actually arm them with knowledge of revising approach to research without disappointing them and breaking any desire to make research.

- To bring the reviews and educational articles with comprehensive analysis of current evidence on topics of interest written by experts to specialists in cardiovascular medicine (cardiologists and cardiovascular surgeons), electrophysiologists, interventionists, cardiovascular imaging specialists, internal medicine with wide range of subspecialties, public health and all relevant specialties.

- To provide a platform for discussion and scientific debate of interest for readers on published research articles, wide range of topics, including guidelines, advances in medical care and industry/technology, education in medicine, health policies and other matters of interest and issues raised by readers and authors of the journal.

- To contribute to education of prasticizing specialists and family physicians, residents and fellows in training and students of medical faculties by publishing rare and well-described clinical case reports, their management, as well as cases, reports, describing successful utilization of new techniques and new tools reflecting advancements in medical industry.

- Overall, to provide the journal services capable of delivering unbiased independent internal and external peer-review by international experts on the topic of relevant to research manuscripts, reviews and case reports

- To provide the peer-review by diverse international reviewers and editorial board from different countries having expertise in the field

- To provide the journal services based on international principles of publishing ethics (authorship, human and animal rights, conflict of interest, etc) and base the

Address for Correspondence: Editorial Office, Heart Vessels\&Transplantation, Togolok Moldo St 3

Bishkek, Kyrgyzstan, Email: info@hvt-journal.com, Phone : 996-312-899 443

Received: 15.12.2016 Accepted for publication: 5.01.2017

Copyright@ 2017 Heart Vessels\&Transplantation 
Our Mission

editorial policies on transparent, unbiased principles and in accordance with rules set by international committees as ICMJE, COPE, WAME etc.

We as an international editorial team, will put all our efforts to fulfill all the above-mentioned goals, and do our best in delivering the independent unbiased peer-review, be transparent in our editorial work, follow principles of international diversity of authors, reviewers and editorial board members, the principles that aims to help our readers receive the hot topic knowledge updates without delay and give opportunity to authors to get fair unbiased peerreview evaluation and publish their original research articles and case reports thus giving a chance to share with international scientific and clinicians community their work.

\section{Editors of Heart Vessels and Transplantation}

